\title{
Optimization of Approaches to the Management of Investment Projects in Regions of Russia
}

\author{
Olesya A. Stroeva \\ Russian Presidential Academy of National Economy and Public Administration, Moscow, Russian Federation \\ Email: stroeva-olesya@mail.ru \\ Lyudmila I. Shinkareva
}

Russian Presidential Academy of National Economy and Public Administration, Moscow, Russian Federation

Innara R. Lyapina

State University - Education-Science-Production Complex, Orel, Russian Federation

Elena V. Petruchina

Orel State University, Orel, Russian Federation

\section{Doi:10.5901/mjss.2015.v6n3s6p87}

\section{Abstract}

High level of development of regions of Russia is impossible without effective management of investment activity at the mesolevel. That's why the purpose of the research is to study and search for optimal approaches to the management of implementation of top-priority investment projects in regions of Russia. During the study, the authors used the methods of financial and economic analysis, planning and forecast, building classifications, comparing, specification, and generalization. As a result, it was found that during management of investment activities in the regions it is advisable to use one of the two models of growth of investment activity: "Top-Down" model (in regions with low current level of economic activity and investment attractiveness) or "Bottom-Up" model (in investment attractive regions with a rather high level of business activity). Besides, the support for activation of investment process in the Russian regions should be ensured by regional structures which guarantee a complex support for investment projects (preparation of investment platforms with all necessary communications, marketing support, etc.). At that, the used tools of support for investment initiatives should be target-focused, according to territorial (sectorial) priorities. This approach will eventually facilitate the increase of investment attractiveness of the regions and formation of favorable investment climate, and will allow improving perspectives of their economic development due to emergence of new markets and participation in new spheres of economic activities.

Keywords: investment process in a region, models of investment activity growth, management of investment projects, support for implementation of investment projects.

\section{Introduction}

Studying the problems of investments has always been in the center of attention of economic science. This is caused by the fact that investments relate to the deepest foundations of economy, determining the process of economic growth as a whole. Activation of investment process is one of the most effective mechanisms of socio-economic transformations.

At present, there is a necessity for deep theoretical study of market forms and mechanisms of investment activity on micro- and macro-levels. An important issue is theoretical substantiation of criteria of efficiency of investment expenses, interconnection, and interdependence of capital investments and structural changes in economy, of determining priorities in sectorial structure of investments, and within main spheres of economy. Study of sources and means of formation of investment resources under modern conditions is also very important.

Investment decisions are one of the most difficult as to the procedure of choosing. They are based on multivariant and multi-criteria evaluation of the variety of factors and tendencies, which are usually multidirectional (Vilenskiy, 2013).

Territorial aspect of direct investments and their dedication to a certain country, region, or territory are doubtless. That's why the evaluation of investment attractiveness of a territory is the most important aspect of any investment 
decision making. It determined the consequences for investor and economy of a region and a country in whole. The more complicated the situation is, the more the experience and intuition of investor should be based on the results of expert evaluation of investment climate in countries and regions (Neshitoy, 2010).

History of evaluations of investment attractiveness or investment climate or the countries of the world accounts for more than 30 years. The first such evaluations were developed and used by Western experts in mid-1960s. One of the first studies in this sphere was the research of Harvard Business School. The basis for comparing was the expert scale that included the following characteristic of each country: legal conditions for foreign and national investors, possibility for export of capital, state of national currency, political situation in the country, inflation rate, and possibility for use of national capital. This range of indicators was not specific enough for adequate reflection of the whole complex of conditions which are usually taken into account by investors (Aksenova, 2012).

That's why further development of methodological apparatus of comparative evaluation of countries' attractiveness took the path of expansion and complication of the system of parameters, which are evaluated by experts, and of introduction of quantitative (statistical) indicators. The following parameters and indicators were used most often:

- $\quad$ type of economic system;

- macro-economic indicators (GNP, structure of economy, etc.);

- volume of natural resources;

- $\quad$ state of infrastructure;

- conditions of development of external trade;

- $\quad$ state's participation in economy.

Emergence of a respectable category of countries with transitional economy and specific conditions of investing at the end of 1980s required the development of special methodical approaches. In respect to these countries, in the beginning of 1990s a couple of expert groups (consulting company "Plan Econ", "Fortune" and "Multinational Business" magazines, etc.), independently of each other, developed simplified methodologies for comparative evaluation of investment attractiveness. They took into account not only conditions but results of investing, proximity of a country to global economic centers, scale of institutional transformations, "democratic traditions", state and perspectives of reforms, and quality of labor resources.

At present, complex rankings of investment attractiveness of the countries of the world are periodically published by the leading economic magazines of the world: Euromoney, Fortune, The Economist (Khakhanovich, 2011).

The Euromoney magazine ranking is the most famous and quoted complex evaluation of investment attractiveness of the countries worldwide; the evaluation of investment risk and countries' reliability is performed twice per year (March and September) on the basis of this ranking. The evaluation uses nine groups of indicators:

- efficiency of economy;

- level of political risk;

- state of debt;

- failure of debt servicing;

- creditability;

- accessibility of bank loans;

- accessibility of short-term financing;

- accessibility of long-term loan capital;

- probability of emergence of force majeure circumstances.

Values of these indicators are determined with the help of experts or by calculations and analysis. They are measured according to 10-score scale and then weighted as to the value of one or another indicator and its contribution into final score. It should be noted that methodical approaches for building this ranking and list of indicators of evaluation are constantly reconsidered by the authors, depending on the change of environment of the global market (Aganina, 2013).

During decision making, the portfolio investors focus on special financial or credit rankings of the countries. Development of these rankings is performed by the most famous expert agencies of the "big six": Moody's, Arthur Andersen, Standart \& Poor' s, IBCA, etc.

In many countries, one of the most popular forms of implementation of investment policy is the system of programs and projects; program-targeted management of investment activities is one the effective methodological approaches with high efficiency and good results.

In the developed countries, a state investment order is used, as a regulating tool. The significance of this tool is caused by the role of investments in the process of regulating industrial development, determined by the ratio of economic and investment cycles (Sibirskaya \& Stroeva, 2010). 
Ideology of public-private partnership spread widely in foreign countries; it ensured the distribution of risks and incomes of investment activity on the basis of combining resources of public and private sectors. The leaders in the sphere of public-private partnership are Great Britain, USA, France, and Germany.

A large importance in regulation and management of investment activity in the developed countries belongs to tax and amortization policy, tax exemptions, in particular, so called investment loan (Fazrakhmanova, 2013). At that, the forms of tax investment incentives, set in different countries, conform to specific economic conditions and tasks of industrial policy. Besides, it should be noted that these incentives might strongly differ depending on the specifics of local conditions, implementation of development programs, capital dispersion, etc. A peculiar tendency, manifesting itself in recent years, is the further stimulation of investment activity through direct reduction of taxes and use of various forms of tax credit and subsidies.

\section{Research Methods}

Methodological basis for the research are general scientific methods of logical, comparative, and systemic analysis, and also statistical methods. Also, the research is based on the use of methods and means of financial and economic analysis, planning and forecast, building classification, comparison, specification, and generalization.

Different regions are peculiar for different models of innovational activities growth. It is possible to allocate 2 main variants - so called Top-Down and Bottom-Up approaches (Figure 1) (Rimer, 2010).

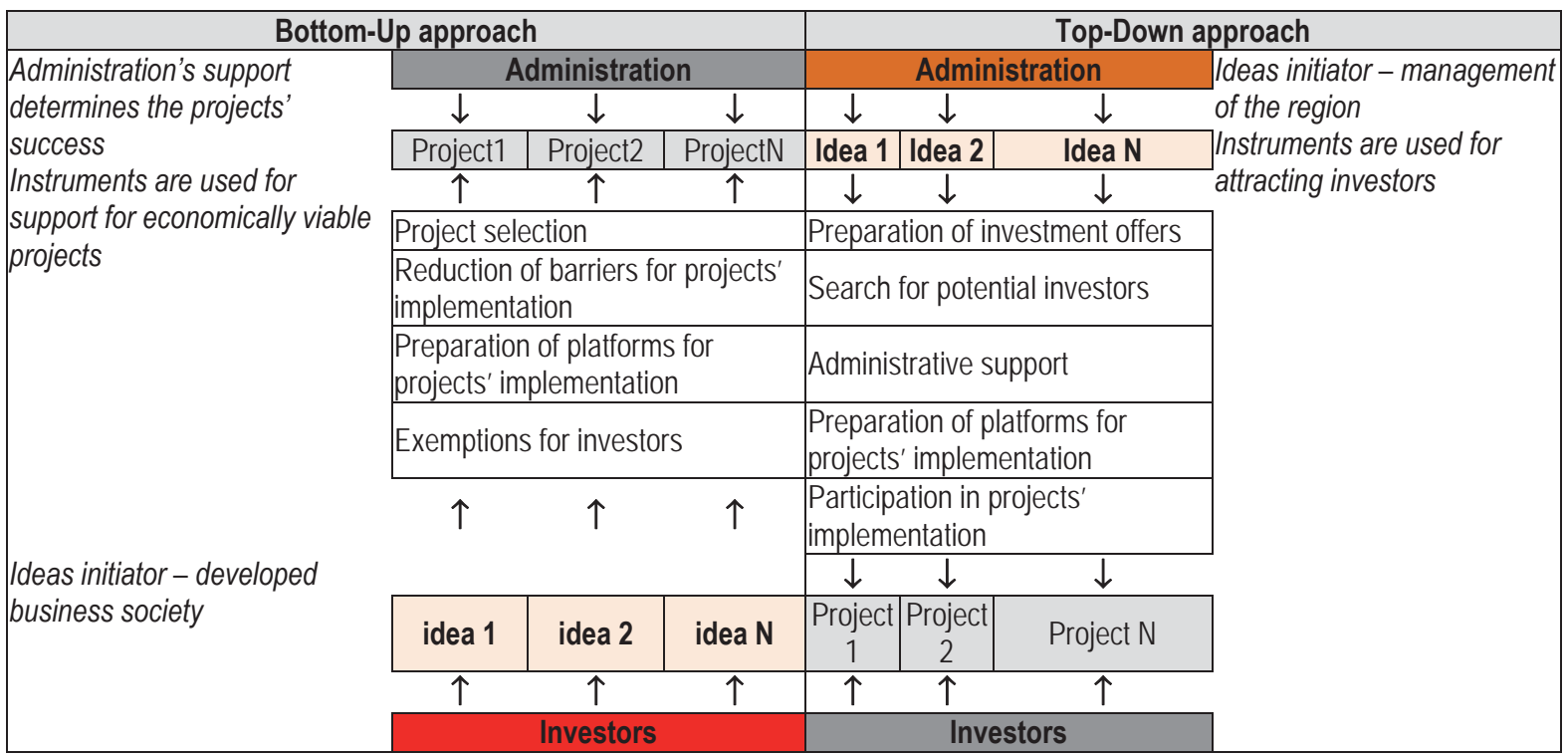

Figure 1 - Approaches to increase of investment activity in region.

Top-Down model supposes that the main source of investment activity is the region's authorities - its government, administration, and municipal bodies. They are the source of investment ideas and projects; at that, the variants of support for these projects' implementation are developed (Merkulov, 2010). Then, there come the existing corresponding bodies of executive power and existing instruments of support for investment activity which perform the following steps:

- preparation of investment offers

- search for potential investors

- administrative support

- preparation of platforms for projects' implementation

- participation in projects' implementation.

Thus, the attraction of required investors and creation of necessary work conditions are ensured.

This model is peculiar for regions with low current level of economic activity and investment attractiveness, which have ambitious goals, clear strategy of development, and vivid investment priorities realized within the corresponding investment policy (Yankovskiy, 2012). The regions in which such model achieved success in 2000s include Kaluga, Lipetsk, and Leningrad Oblasts.

Another model, Bottom-Up, is implemented in the investment attractive regions with high level of business activity. 
Here, active business is the source of ideas and projects, including those which require active support from the region's authorities. Within this model, the role of executive power is to direct the flow of investment activity in the channel that if profitable from the point of view of achievement of key strategic goals and to create conditions for successful implementation of projects and support for high level of business activity.

Thus, it refers not to generation of investment projects at the expenses of the region's Administration but to selection of the projects that conform to the strategic priorities of the region and will be supported during implementation.

\section{Results}

Most of the studied Russian regions have high general indicators of economic development, attract large volumes of investments, and occupy good positions in investment rankings (Sibirskaya \& Stroeva \& Serebrykova \& Petruchina, 2014). At that, vast majority of economic activity and investments belong to sectors of natural resources, the possibilities of the region's authorities in which are limited. In other sectors of economy business activity is not so high, and their investment attractiveness is influenced by a variety of substantial negative factors.

Accordingly, for the purpose of realization of investment strategy of such regions it is advisable to use Top-Down approach. The experts' and potential investors' opinion is unanimous: successful realization of economically effective projects in Russian regions in all spheres, except resources extraction, requires active support of the regions' administration.

At present, the realization of Top-Down approach in most regions of Central federal district began de-facto. Upon an initiative of the district's administration, and, according to strategic goals of the region, there was developed the Investment strategy with investment offers for top-priority investment projects. Their realization requires:

- formation of regional structure for supporting investments;

- preparation of platforms for realization of investment projects;

- ensure attraction of investors, which requires:

- creation of the region's brand;

- $\quad$ ensuring marketing support for top-priority projects;

- forming direct contacts with potential investors;

- ensuring necessary support for projects' realization (including material, financial, administrative, informational, etc.).

Tasks of activation of investment process in the region and of support for projects' realization, as a rule, cannot be solved by means of executive power of the region. Experience of the Russian (and foreign) regions that are most successful in attracting investments shows that performance of these tasks is a responsibility of a special strong structure, created by the region; this group possesses all functions of complex support for investment projects, which include:

- preparation of investment offers;

- preparation of investment platforms and provision of all necessary communications;

- financial support for investment projects, including attraction of regional and federal institutes of financing investments;

- direct participation in the role of investor (development) in realization of certain projects;

- marketing support for projects;

- consulting and administrative support for projects.

This structure can have the form of Corporation of development in the form of joint-stock company, the founders of which may be the region's administration, Vneshekonombank of Russia, and, probably, interested investors. The corporation may be a profitable enterprise and may attract funds from private and public investors. Regions with working Corporations of development include Krasnoyarsk Krai, Kaluga Oblast and Ulyanovsk Oblast.

Another variant is creation of a structure that is responsible for activation of investment process in the region - a regional Agency of investments (Agency of development) in the form of unitary enterprise or non-commercial organization. Such an organization's purposes do not include gaining profit, its goal is to effectively manage budget funds in order to increase investment activity and successfully realize top-priority projects. These structures are created in Volgograd Oblast, Rostov Oblast, Tyumen Oblast, and Kaliningrad.

The third variant supposes the emphasis on the financial component of the structure for complex support for investment projects - in this case, it can exist in the form of a Fund, for example, nonprofit organization "Fund for innovative development of Orel Oblast". This requires re-consideration of constituent and regulatory documents of the Fund, detailed description of its functions and tasks in short-term and mid-term, correction of organizational structure, and formation of registered capital which conforms to new tasks of the Funds. Besides, it is obvious that effective work requires highly skilled specialists with relevant experience to be involved with the Fund. 
The last variant has an advantage - besides solving tasks of complex support for projects, it can become a starting platform for creation of full perspective financial and innovative infrastructure of a region. The following issues can be elaborated within the Fund: basis for creation of the Fund for innovative research and Scientific and educational center of the region, effective technical infrastructure, prototypes of the Fund for innovative projects and Venture Fund of the region. The Innovative Fund of the region may require the development of concepts and business plans, architectural projects, and strategies of these organizations, which have to ensure the region's leadership in the rankings of investment attractiveness (Nelson, 1993; Ludvall, 1992).

Concept of formation of region's leadership in the rankings of investment attractiveness is an integral part of development of investment strategy, as the status of region-leader allows qualitatively improving the perspectives of its economic development by means of opening new markets, participating in new spheres of economic activities, and promoting the products more effectively. Besides, effective use of the region's brand allows increasing the level of added value in the products manufactured in the region.

As a result of conducted work, the main attributes of territories-leaders were formulated which may become the criteria for selection of specific goals and projects, aimed at the development of the region's leadership. Territory-leader provides the services for other territories of its district.

This can be provision of services in the spheres of state administration, international cooperation, finances, consulting, engineering, research, education, mass media and informational services, exhibitions and events, trade, transport and logistics, and tourism. Territory-leader is an example for imitation and it concentrates the best practices, which the other territories strive to adopt (in all spheres of activity, from state administration to everyday culture).

At present, most northern regions of Russia are clients (recipients) of regions-leaders which are represented by various "capitals". At that, they most often use the services of such cities as Tyumen, Moscow, and Ekaterinburg, which provide almost all above mentioned types of services for regions-recipients. Besides, the services in the spheres of engineering and education are actively provided by Novosibirsk, St. Petersburg, and Krasnoyarsk, while Murmansk, which is de-facto a "capital" of Northern Sea Route, provides transport and logistics services. Besides, the region may not have a niche in Arctic symbolic environment, which will weaken its positions during formation of the brand. However, despite the current situation, the economic resources and investment potential for active long-term development in the region can be a sufficient basis for growth of leadership potential.

Thus, the region's brand should be based on: region-wide symbols; leading cities of the district which strive for economic leadership in their niches; branded local territories; organizations and companies that achieve leadership in specific spheres and in specific markets.

A typical model for development of methodology for optimization of approaches to management of implementation of top-priority investment projects in northern regions of the Russian Federation is Yamalo-Nenets Autonomous District.

The target macro-region, "market", and environment for positioning of Yamal is the global Arctic macro-region. It should be noted that as of now the Arctic Region is a geopolitical space with growing global importance. There is a range of political, scientific, and public organizations, focused at the provision of services for it. Thus, the district will have to work in close competitive environment and clearly determine its niche in the Arctic space.

Effective development of service functions in the region requires creation of comprehensive cluster of services with feed each other as to resources and functionality. The projects that are the most effective for the development of leadership can be divided into three groups: financial services, technological scientific \& innovative services, and communicational services.

As the main competitive advantage of Yamalo-Nenets Autonomous District in the struggle for leadership in Arctic is economic resources, financial services are a powerhouse for new vector of the region's development. The district should have a modern and effective financial infrastructure that ensures financing of various Arctic initiatives which could become a successful object for investments and provide resources for development of services that are important for the region's leadership. As the most perspective spheres of investing will be new technologies and scientific \& innovative projects, the financial structure should be closely connected to innovational infrastructure of the region.

Creation of financial and innovational infrastructure of YNAD should be aimed at the diversification of the region's economy, creation of portfolio of non-energy assets and assignment of a new status to the region, which will allow it to ensure sustainable development in long-term (Sverker \& Staffan \& Soren \& Christer \& Teknlic, 2000). For these purposes, the region has to solve a range of important tasks: create a mechanism of effective investing of regional funds; attract the assets of private Russian and foreign investors into regional financial institutes; create competences in scientific and innovational sphere of the region.

Among the measures for improving implementation of investment projects, the development and support for small business should be paid special attention. 
Solving the issue of diversification of YNAD's economy is impossible without development of small and medium business. Small business provides stability of economy and employment - and even during the 2008-2009 crisis, the dynamics of small business, including in YNAD, was positive as compared to decline of Russia's economy.

As of 2014, the level of development of small entrepreneurship lags behind the most regions of the Russian Federation and similar foreign countries.

At that, as to the rates of growth of revenue small enterprises, YNAD has been one of the leaders in the Russian Federation during recent years, which shows efficiency of the implemented programs of support (Table 1).

Table 1 - Yamalo-Nenets Autonomous District's ranking among regions of the Russian Federation as to key indicators of small entrepreneurship development level

\begin{tabular}{|l|c|c|c|}
\hline Ranking's indicators & 2013 & Ratio & 2014 \\
\hline Number of small enterprises for 100,000 people & 76 & $\sim$ & 75 \\
\hline Share of the number of small enterprises' employees in the total number of the employed & 81 & $\sim$ & 80 \\
\hline Revenue of small enterprises per capita & 68 & $\uparrow$ & 58 \\
\hline Rate of growth of small enterprises' revenue & 15 & $\sim$ & 18 \\
\hline Volume of investments into main capital of small enterprises per capita & 81 & $\uparrow$ & 36 \\
\hline
\end{tabular}

According to survey of entrepreneurs, the main problems of YNAD include unfavorable tax administering, lack of highlyqualified staff, and low level of development of financial system; at that, the situation with safety and level of corruption is rather good. Also, there is a problem of informational provision of small business, as most of entrepreneurs are not even aware of existing support measures.

The largest potential for development of small business is observed in trade and services for population, business services, transport and connection, building, housing and public utilities, development of small hydrocarbon deposits, use of associated petroleum gas, ecological services, processing of deer farming production, fishing and fish processing.

State policy of support for small and medium business should work for achievement of key strategic goals of the region's development (Figure 2).

Achieving the goal of improvement of living standards of the population will correspond to support for business oriented at the development of consumer market and services for population, creation of vivid public environment and public spaces, development of housing development and public \& housing utilities and transport \& connection. Innovational enterprises require help, as there is a task to form the innovational leadership of YNAD. The task of diversification of economy requires support for organizations which form the active business environment and provide various business services for other companies. Provision of sustainable development supposes not only diversified economy, but effective natural resource use, which shows the necessity for top-priority support for entrepreneurs who work in the spheres of ecology, waste processing, recultivation of lands, and processing of oil and gas production and utilization of associated gas. The above mentioned sectorial priorities have to be reflected in the district program of small business support.

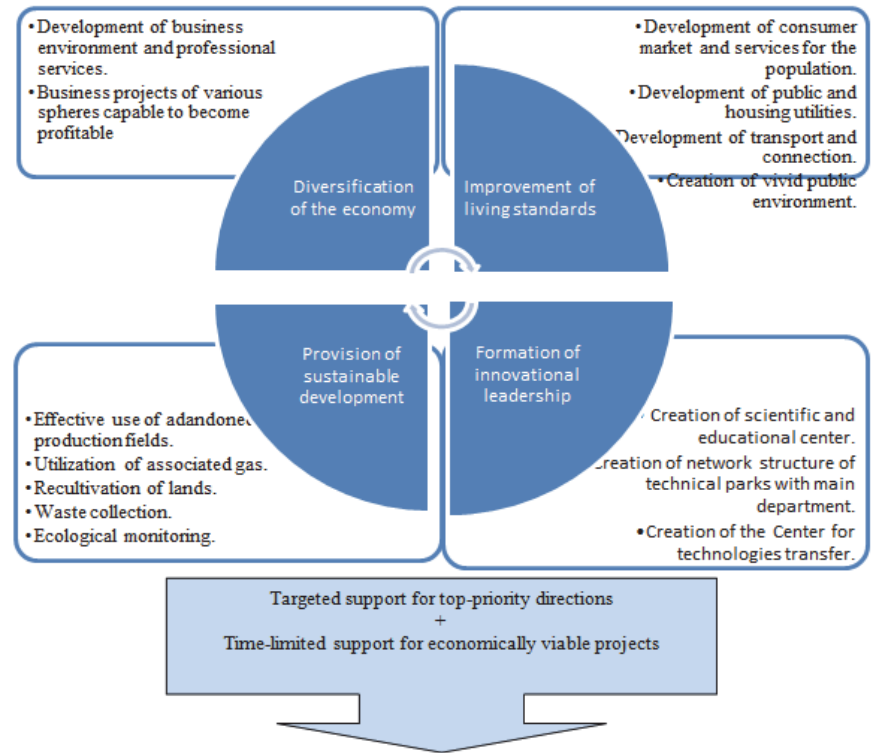

Figure 2 - State policy of support for small and medium business in the region 
Primarily, the tools of financial and material support should be target-focused, according to sectorial priorities. Approach to support for all other projects of small business should be based on a principle that business should be economically viable and reach breakeven point at least in the second or third year of their existence.

Except for assignment of sectorial priorities of support, activation of development of small and medium business in the region requires the following measures:

- creation of informational center for small entrepreneurship in the form of outsourcing;

- provision of policy of outsourcing of some functions of district and municipal organizations;

- development of the mechanism and implementation of practice of service contracts in public and housing utilities, roads, and other spheres;

- creation of educational center of small business;

- the limit of the Guarantee Fund should be increased up to RUB 30 million;

- certification and skills upgrade of managers and specialists of the system of support for small business and innovations, including study placement.

At present, companies-investors of YNAD realize only the top-priority projects. According to forecast of the Russian specialists, the basis for the further socio-economic development of the autonomous district is realization of large investment projects (a list of the most perspective projects in various spheres, the total volume of which constitutes around RUB 11.7 trillion, is prepared).

According to socio-economic forecast, by 2020 , the gross regional product will constitute RUB 1,629 billion, gross regional product per capita - RUB 2,716 thousand, YNAD's consolidated budget revenue - RUB 156.6 billion.

The increase of efficiency of mechanism of state management of investment process requires:

- provision of guarantees for foreign and domestic investors, including by means of deposit and insurance operations;

- attraction of domestic and foreign capital and financing of regional projects.

Besides, a significant problem that limits the investment project is rise of interest of legal entities and individuals, which conduct entrepreneurial activity without registering a legal entity, in increase of the volumes of manufacture of goods, works, and services, attraction of foreign and domestic investments into economy of autonomous district, providing financial support for certain sectors of economy of YNAD.

It should be noted that investment process should be supported by regional and municipal programs, public authorities, production and investment plans of companies, and entrepreneurial activity of the region's population (Nikolenko, 2012).

Thus, Yamalo-Nenets Autonomous District has high indicators of economic development, attracts a lot of investments, and holds good positions in investment rankings. However, greater part of economic activity and investments relate to the sector of oil and gas production, which the region's authorities cannot influence much. Business activity is not so high in other spheres of economy, and their investment attractiveness is influenced by variety of substantial negative factors. That's why the realization of investment strategy if YNAD requires the use of Top-Down approach.

\section{Conclusions}

Efficiency of the offered measures for development of top-priority investment projects of Russia's regions by the example of Yamalo-Nenets Autonomous District consists primarily in optimal choice of investment approach in view of specifics of development of innovational potential of YMAD, climate conditions, economy, and history of development. The measures for improvement of realization of investment projects include development and support for small business. It is impossible to solve the task of diversification of the region's economy without development of small and medium business. Investment process should be supported by regional and municipal programs, public authorities, manufacture and investment plans of the companies, and entrepreneurial activity of the region's population.

\section{References}

Aganina, L.S. (2013). Methods of realization of state innovative policy. Proceedings of scientific conference "Lomonosov - 2013". M.: MSU.

Aksenova, N. (2012). State regulation of foreign investments. Problems of theory and practice of management, 9, 86. Vilenskiy P.L. (2013). Evaluation of efficiency of investment projects. Theory and practice. (2nd edition). M.: Delo.

Merkulov, Y.S. (2010). Investments. M.: INFRA-M. 
Neshitoy, A.S. (2010). Investments. (6th edition). M.: Dashkov and Co.

Nikolenko, E.B. (2012) Organizational and economic mechanism for investment for R\&D: dis. ... of Ph.D.: 08.00.05. UFA.

Rimer, M.I. (2010). Economic evaluation of investments. (3rd edition). SPb.: Piter.

Sibirskaya, E.V., Stroeva O.A. (2010). Methodology for evaluation of the process of investment of innovative activities of regional economic systems. Finansy i kredit. 15, 16.

Fazrakhmanova, A.I. (2013). Evaluation of efficiency of formation and realization of investment policy of enterprise: abstract. Dis. ... of Ph.D.: 08.00.05. Ufa.

Khazanovich, E. S. (2011). Investments. M.: KnoRus.

Yankovskiy, K. P. (2012). Investments. SPb.: Piter.

Lundvall, B. (1992). National Systems of Innovation: Towards a Theory of Innovation and Interactive Learning. London.

Nelson, R. (1993). National Systems of Innovation: A Comparative Analysis Oxford.

Sibirskaya, E.V., Stroeva, O.A., Serebrykova, N.A., Petruchina, E.V. (2014) The Contents and Structure of Innovative Activity in the Russian Economy. Asian Social Science, Vol. 10, 23, 51-60

Sverker, A., Staffan, J., Soren, S., Christer, O. Teknlic, N. (2000). Corporate Innovation Systems. Goteborg: Chalmers University of Technology. 